\title{
Evidencias del uso político de la ciencia médica en un artículo de la prensa brasileña alusivo al presidente de Chile José Manuel Balmaceda en 1891
}

\author{
Evidence of the political use of medical science in a \\ Brazilian newspaper article on the Chilean president \\ José Manuel Balmaceda in 1891
}

\author{
Mario Fabregat ${ }^{i}$ \\ 'Académico, Departamento de \\ Ciencias Sociales/Universidad de la \\ Frontera. \\ Temuco - Provincia de Cautín - \\ Chile \\ orcid.org/0000-0002-2369-2869 \\ mario.fabregat@ufrontera.cl
}

Recebido em 7 mar. 2018. Aprovado em 5 abr. 2018.
FABREGAT, Mario. Evidencias del uso político de la ciencia médica en un artículo de la prensa brasileña alusivo al presidente de Chile José Manuel Balmaceda en 1891. História, Ciências, Saúde - Manguinhos, Rio de Janeiro, v.26, n.2, abr.-jun. 2019, p.657-672.

\section{Resumen}

En medio de la Guerra Civil ocurrida en Chile el año 1891, apareció publicado en el periódico brasileño Diário de Campinas el artículo titulado "Balmaceda", de autoría de Joaquim Nogueira de Sá Itagiba, donde analiza el delirio del político chileno José Manuel Balmaceda, presidente de la República entre 1886 y 1891, explicando su comportamiento, definido como el característico del dictador y el tirano. El artículo es pródigo en la utilización de diversas teorías alienistas que intentan identificar al sujeto criminal, respondiendo a los ideales de normalización social. El artículo forma parte del libro La prensa extranjera y la dictadura chilena, de Alberto Fagalde, publicado en 1891, en Chile.

Palabras clave: Brasil; Chile; prensa; frenología; alienismo.

Abstract

In the midst of the Civil War in Chile in 1891, the Brazilian newspaper Diário de Campinas published an article entitled "Balmaceda," by Joaquim Nogueira de Sá Itagiba, which analyzes the delirium of Chilean politician José Manuel Balmaceda, president of the Republic from 1886 to 1891 in order to explain his behavior, which it defines as characteristic of a dictator and a tyrant. The article makes liberal use of various psychiatric theories that sought to identify the criminal subject in response to ideals of social normalization. The article was part of the book La prensa extranjera y la dictadura chilena, by Alberto Fagalde, published in 1891, in Chile.

Keywords: Brazil; Chile; press; phrenology; psychiatry. 


\section{Sobre el uso político de la medicina y la ciencia en Latinoamérica}

Dentro de la psiquiatría europea de la segunda mitad del siglo XIX, los estudios de la mente dieron cabida a diversos saberes y teorías, como la frenología y el degeneracionismo, los que surcaron caminos que rebasaron el ámbito médico, tributando a otros como la criminología positivista, desarrollada en Italia a fines del mismo siglo. A su vez, sobre todo el degeneracionismo, encontró una línea de continuidad con la eugenesia y su propuesta política de intervención social (Sánchez, 2014).

En la dinámica de la circulación de teorías médicas surgidas en Europa, el arribo de éstas a Latinoamérica implicó recepcionarlas de acuerdo a los contextos locales. En el caso de la frenología, creada por el anatomista alemán Franz Joseph Gall (1806, p.7475), a fines del siglo XVIII, y que sostuvo el desciframiento de lo psíquico a partir de las características del cráneo, existen evidencias de su arribo a México en la primera mitad del siglo XIX (Pavón-Cuellar, 2013), a Brasil y Argentina en el último tercio del siglo XIX (Barros, 2005; Spota, 2014) e indirectamente a Chile por medio de la eugenesia a principios del XX (Sánchez, 2014). Sobre esta última se ha señalado que dado el acervo cultural de predominio católico en la región, su teorización e implementación determinó un estilo más blando que el definido en el marco anglosajón directamente racista (Stepan, 2005) a diferencia de uno latinoamericano centrado en la educación sexual, la higiene y la prevención de enfermedades. Esta perspectiva ha tenido ciertas críticas, apareciendo algunos autores desmitificando o matizando esta supuesta coerción débil en la eugenesia latinoamericana (Miranda, 2003; Biagini, 2007; Vallejo, Miranda, 2014; Armus, 2016).

Sobre el uso y desarrollo en la región de algunas de las teorías médicas ya mencionadas, hemos encontrado en la obra de Alberto Fagalde (1891) La prensa estranjera y la dictadura chilena un artículo publicado en el periódico brasileño Diário de Campinas, titulado "Balmaceda", escrito por uno de sus redactores, Joaquim Nogueira de Sá Itagiba. Dicha publicación originalmente en portugués y reproducida por Fagalde en español - realiza un descarnado análisis frenológico del presidente chileno José Manuel Balmaceda, quien había asumido el cargo el año 1886 y que al finalizar su período, en 1891, se vio envuelto en un proceso revolucionario que implicó su derrota militar y su posterior suicidio.

La trayectoria del conflicto armado se originó en el marco de un sistema político que podríamos llamar "presidencialista" donde el Congreso, progresivamente, empezó a ganar poder a costa del Ejecutivo. El año clave fue 1890 cuando el Congreso no aprobó la ley de presupuesto de la nación para el año siguiente, frente a lo cual Balmaceda reaccionó aprobando esta ley mediante decreto gubernamental el $1^{\circ}$ de enero de 1891 . Este procedimiento no estaba contemplado en la Constitución, razón por la cual el Congreso, con el apoyo de la Escuadra Nacional, se sublevó contra el gobierno acusado de convertirse en dictadura lo que hizo estallar la Revolución de 1891 (Bañados, 1894).

La derrota balmacedista marcó el inicio de un período político conocido como "parlamentarismo criollo" (1891-1925) donde la figura presidencial quedó subyugada al poder del Congreso en manos de una oligarquía parlamentaria.

Por un lado, el artículo firmado por Itagiba hace uso del saber médico en medio de un proceso político de alta intensidad, por el otro, alude a la frenología, al alienismo, a la 
criminología positivista y al degeneracionismo, resultando este último un antecedente de la eugenesia. Consideramos que su análisis es necesario y pertinente para la comprensión del decantamiento de los saberes médicos situados en espacios que culturalmente fueron considerados para la época en los bordes de la modernidad. En el caso particular de Brasil, sobre todo en el periodo inmediatamente anterior a la de constitución de la República, surgieron algunos intelectuales definidos como inmigracionistas con una clara inclinación eugénica (Tavares Bastos y Louis Couty) que propiciaron la venida de europeos para que blanquearan la población y actuaran como catalizadores del progreso y la civilización (Velasco, 2015).

La Proclamación de la República en 1889 y la promulgación de la Constitución de 1891 dotaron a Brasil de un contexto propicio para el desarrollo del liberalismo, situación que explica en parte el apoyo de uno de los redactores del Diário de Campinas (Itagiba) al bando parlamentario opositor al "dictador" Balmaceda. Lo relevante de este apoyo es que la figura del mandatario chileno es atacada políticamente desde una perspectiva novedosa: sus características mentales.

En Chile, la condición mental del presidente Balmaceda fue abordada principalmente porque había tomado la determinación de suicidarse. Surgieron algunos discursos que colocaron en perspectiva argumentos médicos cuestionando su salud mental (San Francisco, 2006). Estos fueron realizados por políticos e intelectuales de la época que usaron la locura como metáfora de abuso de poder; otros, en cambio, de manera directa delinearon argumentos conceptuales que hablaban de neurosis orgánica del cerebro, característico de un loco, o de que la fisonomía de Balmaceda no pasaría inadvertida para ningún especialista (Letelier, 1890; Salas, 1914; Montt, 1891).

La década de 1920 se siguió escribiendo acerca de los sucesos acaecidos en 1891, pero principalmente enfocándose en analizar el conflicto político-gubernamental. Esporádicamente se observa en algunos intelectuales la penetración del lenguaje alienista para fundamentar la trayectoria política de Balmaceda, aludiendo a su genealogía, sus características físicas y sus rasgos faciales (Rodríguez, 1921). No detectamos directa presencia médica en estos análisis.

Al despuntar el siglo XX e independientes del "caso Balmaceda", aparecieron en Chile las primeras retóricas de tipo racial que representaron un incipiente discurso eugenésico dirigido a enaltecer el carácter mestizo chileno (araucano y español), condición que debía fomentarse por medio del nacionalismo (Palacios, 1918).

Respecto al alienismo podemos señalar que hacia fines del siglo XIX, éste comenzó a circular de manera incipiente en la elite chilena, "contagiando" el discurso político de la época. Esto explica que un cuarto de siglo después de la revolución antibalmacedista, un destacado jurista chileno animado, según él, por el espíritu histórico que intentaba comprender dicho proceso de una manera desapasionada y objetiva, iniciara su obra con la biografía de Balmaceda, dejando un espacio para analizar su fisonomía. No se trataba solo de una descripción física, sino que de la búsqueda de antecedentes y evidencias que se conectaran con sus decisiones políticas, por lo tanto, no era un hecho baladí conocer sus rasgos, su fisonomía moral, porque detrás de ellos, se infería un comportamiento distinguido: 
Su cabellera rubia y echada hacia atrás, lucía hermosos rizos, a semejanza de los antiguos poetas; sus ojos azules, profundos, revelaban un espíritu reflexivo y siempre dominado por alguna idea; la frente amplia y bien preñada; su nariz borbónica, especialmente apta para llevar a sus pulmones el oxígeno necesario para vigorizar su expresión; la boca regular y de labios finos, permanecía siempre entre abierta, acaso para dar pronta salida a la palabra que era su arma de combate; y, por fin, su rostro cortado en forma de ángulo agudo, formaba un conjunto simpático, atrayente, y hacía comprender que por sus venas sólo corría sangre europea (Rodríguez, 1921, p.16).

Sin embargo, no hemos encontrado ninguna publicación como la del artículo del Diário de Campinas, que haya tratado de forma tan directa un fenómeno político desde el saber médico. Allí se intenta explicar el comportamiento despiadado y sanguinario del presidente de Chile que, como se dice, ha devenido en dictador y tirano. Para Itagiba, el ejercicio del poder y la responsabilidad que le cabe en la tragedia política de 1891, lo ubican cerca del degenerado mental y del criminal, y es en su historia clínica donde se encontrarían los antecedentes de sus males:

También no hace muchos años que el Tirano, por poco no fue víctima de una fiebre palúdica complicada con otros desarreglos de su organismo.

Unánimes están los más aventajados antropólogos-psicopatas en considerar las manifestaciones violentas de pasiones amorosas como causa, a veces, de una complicación en el sistema nervioso, que después puede degenerar en casos psicosomáticos declarados.

¿Quién nos podrá decir que Balmaceda haya escapado a esos peligros y que no fuese paciente de tal o cual afección en la masa encefálica, preparándose para una futura enfermedad epiléptica? (Fagalde, 1891, p.202).

La peligrosidad filosa de Balmaceda también era posible desentrañarla en una suerte de análisis tomográfico de su rostro, el que describía singularidades adscritas a la tipología del mal. El juicio era inimpugnable y categórico porque la insania mental del llamado hipocondríaco vesano chileno tenía una correspondencia orgánica:

Las orejas son regulares y pulposas; la barba es delicadamente redonda; tiene una semejanza con la barba de Henriette Cornier, el célebre monomaniaco homicida, que sirvió de asunto a uno de los más bellos estudios del notable alienista, C. Marc.

La boca es grande y los labios delgados, ocultándose bajo unos sedosos y espesos bigotes que principian a encanecer. En estos últimos tiempos la solía abrir para articular rujidos de cólera, órdenes de ejecuciones temerarias, y asesinatos.

La nariz gruesa, voluminosa y aguileña, tiene cierta semejanza con el agudo pico del cóndor, el terrible rapaz de los Andes..., formando ángulo tras un pequeño surco impreso en cada lado de ella (Fagalde, 1891, p.201).

El análisis fisonómico-mental que se hizo de Balmaceda entendía que las fuerzas políticas que lo combatían no solamente luchaban contra un enemigo que había introducido una entropía en el organismo social, sino que también contra el sujeto desquiciado, portador de una enfermedad altamente letal para la sociedad. Lo razonable, lo moralmente justo y lo sano era derrocarlo. Todos los argumentos civilizados y modernos lo aconsejaban. Balmaceda era la síntesis de la insania mental: hipocondríaco y epiléptico. 
Sin duda, lo interesante es la apelación a este tipo de evidencias para legitimar la veracidad de un relato: la moral y la conducta tenían antecedentes orgánicos. Objetivando las intenciones y los deseos personales en el cuerpo, en un material concreto, se creía avanzar en la fijación de la verdad. De este modo, la racionalidad positivista funcionaba como soporte de las ideas políticas e ideológicas. Por eso es que en el artículo de Itagiba se señalaba que como no se podía practicar una autopsia orgánica al cuerpo de Balmaceda, se procedería con el escalpelo a un análisis de su anatomía para llegar a conclusiones científicas:

Vamos a analizar al Tirano que venimos estudiando y a poner fin con este artículo a las consideraciones que nos sugieren su temperamento especial y sus particularidades singularísimas de hombre público. Puede a primera vista parecer inútil e impertinente un estudio psiquiátrico de ese hombre que nada tuvo de notable; mas, Balmaceda no es hoy simplemente el ex-Presidente de Chile, no, Balmaceda es hoy un tipo, talvez el único en la historia contemporánea, del Dictador perfecto, cruel en extremo, voraz, satánico, y como tal comprendido en las clasificaciones de la criminalidad antropológica, y por lo tanto, un tipo universal (Fagalde, 1891, p.204).

El análisis de la personalidad de Balmaceda concluía retornando a la declaración inicial que se preguntaba si merecía o no castigo por sus perversos crímenes. La respuesta es que el castigo moral ya lo había recibido por parte de la humanidad al declararlo culpable de antemano. No se trepida en definirlo como un reo peligroso al que era necesario inventarle un castigo especial, contemplando como posibilidad cierta "el espacio comprendido entre los helados muros de un manicomio" (Fagalde, 1891, p.207). Se cerraba el análisis con el aserto del enfermo mental que había estado a cargo de los destinos de una nación y que, como era de esperarse, la había arruinado al hundirla en una guerra entre hermanos.

Lo que nos resulta evidente es que Joaquim Nogueira de Sá Itagiba, situándose en la dimensión científica como garantía, intentaba dar pruebas de autonomía política, neutralidad e imparcialidad para fundar sus juicios contrarios al presidente Balmaceda. Pero, como hemos visto en el desarrollo de lo expuesto, esta separación no es efectiva, resultando el lenguaje que él llama de la "ciencia frenológica" un instrumento político al servicio de su causa. Al caracterizar a Balmaceda como un tirano de comportamiento sanguinario, construía el escenario maniqueo entre el sujeto enfermo como encarnación del mal y las fuerzas socio-políticas sanas que encarnaban el bien. Balmaceda cabía dentro de la categoría del delincuente peligroso que había que neutralizar. La medicalización de su comportamiento era un flanco más desde donde se le podía atacar a él y a todos los que franquearan la constitución y la ley.

Probablemente en Chile, el examen mental practicado al español Antonio Ramón Ramón, en 1915, constituya el primer caso en que intervino el alienismo en un suceso político. Ramón intentó, sin éxito, asesinar al general Roberto Silva Renard, acusado de ordenar la matanza de trabajadores en huelga en la ciudad de Iquique. La justicia ordenó el peritaje mental de Ramón, el que fue realizado por los médicos Hugo Lea-Plaza y Germán Greve. Aunque se señala que el informe evidencia los primeros visos del freudismo en la criminología chilena, no se trepida en caracterizar a Ramón como un degenerado mental (Ruperthuz, Sánchez, 2015). 
Así como Ramón no podía estar sano al atentar contra un general de la República, Balmaceda tampoco podía estarlo si había transgredido la ley y conducido a su pueblo a una guerra civil. En ambos casos, quienes definían y delimitaban el orden político, determinaban también quiénes eran los degenerados.

\section{Otros detalles de la publicación brasileña}

El libro de Alberto Fagalde La prensa extranjera y la dictadura chilena fue publicado en Chile en el mes de noviembre de 1891, a dos meses del término de la guerra civil, iniciada a comienzos del mismo año. Se trata de una recopilación de artículos de prensa europeos, angloamericanos y sudamericanos que abordaban los sucesos ocurridos durante el último año de gobierno del presidente José Manuel Balmaceda, comprendiendo desde el estallido de la revolución hasta su suicidio, el 19 de septiembre de 1891. El libro daba cuenta de la cobertura internacional con el objetivo de mostrar el unánime rechazo a lo que el autor llamó dictadura chilena, entregando el sustento de legitimidad a las razones que habían llevado a las fuerzas, llamadas constitucionalistas, a alzarse en armas.

La obra está dividida en tres partes: la dictadura, la caída y el suicidio. Sin embargo, aparece un apéndice, donde se agrega el artículo del Diário de Campinas, periódico lanzado el 20 de septiembre de 1875, en la ciudad de Campinas, en la entonces provincia de São Paulo, y dirigido por Antonio Duarte de Moraes Sarmento. Entre sus redactores estaba Joaquim Nogueira de Sá Itagiba, que escribió el artículo analizado.

Inferimos que fue publicado en el mes de septiembre de 1891 pues, al comienzo del artículo se indica que Balmaceda había sido derrocado "por la revolución que terminó el 30 del pasado", refiriéndose al mes de agosto. Además, el propio Fagalde (1891, p.195), en una nota al pie, precisaba que el artículo había sido escrito antes de que en Brasil se supiera del suicidio de Balmaceda.

El artículo en cuestión pone en evidencia que Itagiba dominaba las teorías alienistas en boga, porque es pródigo en conceptos y términos de esta naturaleza, insistiendo en que a Balmaceda lo estaba analizando a partir de antecedentes anamnésticos y signos anamorésticos. Dentro de los posibles diagnósticos de su patología, alude a la posibilidad de que perteneciera a la tipología del delincuente epiléptico, correspondiente a la tercera categoría, según la clasificación realizada por el doctor Blanche en Los homicidios cometidos por los alienados (1878). Para complementar lo anterior, agrega que, probablemente, Balmaceda sufría de una forma de la neurastenia moral descrita por Benedickt.

También explora la posibilidad de que su insania respondiera a antecedentes de origen congénito, presente según la teoría de Lauvegne, en los criminales de genio. Pero, utilizando la obra de Lombroso, Tratado antropológico experimental del hombre delincuente (1876), descartaba que perteneciera a uno de los tipos de criminal nato, el de genio, afirmando que lo más probable es que le correspondía estar en la clase de los mattoides, un tipo vulgar. Esta conclusión a la que llega se basaba en la información que se manejaba y que hablaba del desenlace de las batallas de Con-Con y La Placilla (21 y 28 de agosto de 1891) que consignaban a Balmaceda como un cobarde, al haber huido luego de la derrota. Sin embargo, Balmaceda se encontraba en la capital, Santiago, a más de cien kilómetros del 
lugar de las hostilidades. Informado de los resultados adversos de las fuerzas militares que lo apoyaban, decidió solicitar refugio en la legación argentina, lugar donde, finalmente, se suicidó.

Todos estos antecedentes eran manejados por Itagiba, pero obviamente funda sus argumentos en una reinterpretación prejuiciada políticamente, al ubicarse en el bando que apoyaba a los revolucionarios. El perfil que construye de Balmaceda posee una fuerte carga de rechazo y discriminación, encarnando al sujeto enfermo que, en este caso, dada su magistratura, potencia de manera superlativa la peligrosidad de su patología. Dicho análisis es hilvanado y construido bajo el amparo de la supuesta neutralidad científica, aunque más bien suena a una representación subjetiva y apasionada de los hechos expuesta con el soporte ilustrado de la racionalidad.

Cabe destacar que a lo largo del artículo, Itagiba cita a los alienistas y a sus obras y otras veces solo precisa sus nombres. Entre ellos aparece A. Corre, Los criminales (1887); Magnan; C. Marc; Lombroso; Lauvergne; Delasiaure, Tratado de la epilepsia (1854); Benedickt; Legrand du Saulle, Estudio médico-legal sobre los epilépticos (1877); Jules Falret, Del estado mental de los epilépticos (1861); Schüle; Richard von Krafft-Ebing, Psicopatía sexual y el portugués Julio de Mattos, La locura (1889). También cita algunos trabajos de la publicación italiana Revista Archivo de Psiquiatría.

Para Itagiba todos estos alienistas representan el colchón ideológico y científico de los argumentos que él mismo emplea para situar a Balmaceda no solo como el "reo peligroso", el "feroz hombre", sino que como el neurasténico criminal congénito. De allí que resulte pertinente que este saber médico analice sus características de personalidad y anatómicas. En cuanto a las primeras, según Itagiba, destacan el egocentrismo y el fanatismo que pueden encontrar sus antecedentes en diversas enfermedades y desarreglos orgánicos. De las segundas aparecen con nitidez la violencia sanguinaria, reflejada en su cuello largo, y la monomanía homicida evidenciada en su mentón. Y es a partir de las evidencias de la historia de vida de Balmaceda, sus rasgos físico-orgánicos y su comportamiento como gobernante que Itagiba concluye que es un tipo de degenerado, el delincuente epiléptico (Fagalde, 1891, p.207).

El sujeto morboso que transgrede la ley y delinque, pudiendo llegar a matar, representa un peligro. Por lo tanto, en opinión de Itagiba, resulta indispensable el auxilio que puede prestarla ciencia alienista para identificarlo y, como en el caso de Balmaceda, mandar a encerrarlo. En este sentido, la lucha por la conservación de la sociedad requiere y necesita que las fuerzas políticas dispongan de todas las herramientas a su alcance. Conceptos de salud, enfermedad, prevención, entre otros, requerirán de la nomenclatura y la cosmovisión médica para ejecutar políticas de control. El artículo de Itagiba es prueba de ello al identificar a Balmaceda con un tipo delictual determinado que hay que neutralizar.

\section{REFERENCIAS}

ARMUS, Diego.

Eugenesia en Buenos Aires: discursos, prácticas, historiografía. História, Ciências, Saúde -

Manguinhos, v.23, supl.1, p.149-170. 2016.
BAÑADOS, Julio.

Balmaceda: su gobierno y la Revolución de 1891. París: Garnier. t.2. 1894. 
BARROS, José.

Indo a Nina Rodrigues: as "premissas" de As raças humanas e a responsabilidade penal do Brasil.

Cadernos Pós Ciências Sociais, v.2, n.4. p.7-31. 2005.

BIAGINI, Hugo.

América Latina, continente enfermo. Polis:

Revista Latinoamericana, n.16. Disponible en:

$<$ http://journals.openedition.org/polis/4665>.

Acceso en: 10 dic. 2017. 2007.

FAGALDE, Alberto.

La prensa extranjera y la dictadura chilena.

Santiago: Imprenta Santiago. 1891.

GALL, Franz Joseph.

Exposición de la doctrina del doctor Gall, o nueva teoría del cerebro, considerando como residencia de las facultades intelectuales y morales del alma. Madrid: Imprenta de Villalpando. 1806.

ITAGIBA, Joaquim Nogueira.

Balmaceda. In: Fagalde, Alberto. La prensa extranjera y la dictadura chilena. Santiago: Imprenta Santiago. p.195-207. 1891.

LETELIER, Valentín.

La acusación. Santiago: Imprenta de la Union. 1890.

MIRANDA, Marisa.

La antorcha de cupido: eugenesia, biopolítica y eugamia en Argentina, 1930-1970. Asclepio, v.55, n.2, p.231-255. 2003.

MONTT, José Miguel.

Víctimas y mártires de la dictadura: siluetas póstumas. Santiago de Chile: Imprenta Santiago. 1891.

PALACIOS, Nicolás.

Raza chilena: un libro escrito por un chileno y para los chilenos. Chile: Imprenta Universitaria. 1918.

PAVÓN-CUELLAR, David.

Entre la ideología y la frenología: la psicología mexicana desde la consumación de la independencia hasta el inicio del Porfiriato. Revista Electrónica de Psicología Iztacala, v.16, n.4, p.1073-1103. 2013.
RODRÍGUEZ, Joaquín.

Balmaceda y el conflicto entre el Congreso y el

Ejecutivo. Santiago de Chile: Gutenberg. 1921.

RUPERTHUZ, Mariano; SÁNCHEZ, Marcelo. Entre la degeneración y el psicoanálisis: una pericia médico legal chilena en 1915. Revista Historia y Justicia, n.4, p.138-168. 2015.

SALAS, Ricardo.

Balmaceda y el parlamentarismo en Chile: un estudio de psicología política chilena. Chile: Universo. 1914.

SÁNCHEZ, Marcelo.

La teoría de la degeneración en Chile (18921915). Historia, v.2, n.47, p.375-400. 2014.

SAN FRANCISCO, Alejandro.

La apoteosis de Balmaceda: desde la tumba solitaria a la gloria (Santiago, 1896). In: McEvoy, Carmen (Ed.). Funerales republicanos en América del Sur: tradición, ritual y nación. 1832-1896.

Chile: Centro de Estudios Bicentenarios; Instituto de Historia/Pontificia Universidad Católica de Chile. p.177-203. 2006.

SPOTA, Julio César.

Aportes para el estudio de la frenología argentina en la segunda mitad del siglo XIX. Tabula Rasa, n.20, p.251-281. 2014.

STEPAN, Nancy Leys.

A hora da eugenia: raça, gênero e nação na América Latina. Rio de Janeiro: Editora Fiocruz. 2005.

VELASCO, Mónica.

Políticas raciales en Brasil: 1862-

1933. Latinoamérica: Revista de Estudios Latinoamericanos, v.61, p.31-64. Disponible en: $<$ https://www.sciencedirect.com/science/article/ pii/S1665857415000290>. Acceso en: 20 ene. 2018. oct. 2015.

VALLEJO, Gustavo; MIRANDA, Marisa. Iglesia católica y eugenesia latina: un constructo teórico para el control social (Argentina, 19241958). Asclepio, v.66, n.2, p.55-66. 2014. 


\section{BALMACEDA $^{1}$ \\ (Diário de Campinas, de 20 sept. 1875, citado em Fagalde, 1891, p.195-207; traducido por Alberto Fagalde).}

Es un tipo humano, innegablemente, José Manuel Balmaceda, derrocado hace poco de la Presidencia de la República por la revolución que terminó el 30 del pasado.

Como Presidente de aquella nación, ya fué juzgado por sus compatriotasy por todo el mundo civilizado que le fue unánimemente contrario. A la historia le toca juzgarlo como estadista, como primer magistrado durante el terrible período de sangre que se levantó en Chile para levantar los avances del progreso; a la ciencia frenológica le toca ahora estudiar la forma de su bella cabeza, desvasar las profundidades de su cerebro que le imprimían ese carácter enérgico y casi rudo.

Resumamos los antecedentes públicos e individuales del tirano vencido, como también sus precedentes.

Ya que no nos es posible hacer su autopsia orgánica, nos es permitido al menos estudiarle con el escalpelo de la investigación sobre su vida de hombre.

Ensayemos un curso anatómico del cual, en general o particular, podamos sacar algunas conclusiones científicas.

Balmaceda era hijo de padres ricos que, por lo tanto, si algún defecto tuvo, sería difícil comprobarlo.

En su infancia, Balmaceda siempre estuvo sujeto a un régimen severo de encierro claustral.

Desde el Seminario, mostró un carácter rebelde, de índole altiva y sobre todo arrogante para con sus propios compañeros de colegio, a los cuales se complacía en mortificar con la autoridad de su linaje "noble".

Se dedicó en seguida a la carrera pública y a la política, llevando en su cerebro regulares conocimientos de sociología y bastante oro, que es lo que causa la codicia de la gran cauda de administradores y padrinos no politiqueros, siempre solícitos e interesados.

Diputado y, en dos ocasiones, ministro del ex-presidente Santa María, desempeñó esos cargos con rara perspicacia y notable energía, aun con dureza; en seguida, mediante los esfuerzos y maquinaciones de su antecesor, fue elegido candidato al elevado puesto de jefe de la nación chilena el 25 de junio de 1886.

Durante su carrera política Balmaceda procuró siempre ocultar, con bien medida hipocresía y feroz ambición que le devoraban las entrañas, el deseo ardiente, casi locura, de ser el jefe de su partido, de ser el supremo director de los destinos de Chile.

El general Veintimilla tornóse luego su confidente íntimo.

Simila cum similibus...

Resolvieron entre sí que el ministro Balmaceda sucediese al presidente Santa María. Entonces aquél fue proclamado jefe del partido de ambos, y luego después Presidente de la República. 
Premunido con el carácter sombrío que se formó en su juventud, y dominado por la filosofía positiva; sectario ardiente de sus dogmas, José Manuel Balmaceda aceptó aquel pesado cargo y lo sirvió con tal habilidad, con tal meditado interés, que fácilmente eludía la menor sospecha que se pudiera abrigar respecto a su programa político-administrativo y a los funestos designios que abrigaba en su mente.

Entre tanto, alimentando ideas tenebrosas, Balmaceda preparaba el lecho para asentar su teoría filosófica y el 7 de enero del corriente año proclamaba con voz de desafío brutal, la dictadura de aquel bello país.

Todos los poderes de la nación se concentraban ahora en su sola mano de fierro.

Balmaceda era, entre tanto, como él mismo lo dijera, la primera y única autoridad pública, el poder unipersonal y soberano absoluto, el "dictador de Chile".

II

Pero el criminal innato, como el criminal por costumbre o accidente, necesita, para mostrarse o manifestarse, l'occasion d' un stimulus, dice Corre.

¿Encontró Balmaceda ese estímulo ocasional?

Lo veremos.

Ocurramos para mejor lucidez de nuestra narración, a los antecedentes históricos de Balmaceda, el gran reo, según la frase usada por Valentin Magalhães.

El moderno tirano que estudiamos, cuenta en su historia ancestral los siguientes datos que caracterizan al individuo predestinado a manifestarse en captata occasio:

(a) Tuvo padres ricos y vivió siempre fastuosamente;

(b) Fue educado con rigidez suma;

(c) Desde su infancia demostró un carácter arrebatado, orgulloso, juzgándose superior a todos, y atrabiliario;

(d) Como era rico, siempre tuvo aduladores que, por cierto, le excitaban más a la soberbia, al amor propio, al egoísmo del fuerte contra el débil;

(e) En la vida pública, como jefe de un partido, fue siempre político apasionado e inexorable para con sus adversarios;

( $f$ ) Calculadamente, se mantenía en absoluta reserva para manifestar sus ambiciones;

(g) En suma, Balmaceda fue siempre intransigente y fanático en doctrinas filosóficas y religiosas, y su propia familia le consideraba dotado de una severidad espartana.

Exaltado al elevado cargo de Presidente en 1886, puesto que debía ocupar por cinco años (Constitución, artículo 51), gobernó bien durante los dos primeros años, más bien por cálculo e interés personal, que como táctica política.

En el tercer año principió a hostilizar a los suyos, comenzando por fraccionar al Partido Liberal, y enemistarlo con los adversarios; al mismo tiempo declaraba abierta lucha a sus adversarios políticos, expulsándolos, desde los más caracterizados y honorables, hasta del más insignificante puesto público.

Arrogándose la jefatura del partido liberal chileno, Balmaceda lo despedazó en fracciones con sus proyectos de mando unipersonal. 
Como presidente, destrozó el partido, cuya unificación había sido mantenida con tantos esfuerzos por los ministros Antúnez y Aníbal Zañartu, y lo subdividió por medio de intrigas calculadas, fraccionando el clerical, el conservador, el nacional y el radical, llegando a ser la política chilena una acerva coalición de partidos rencorosos.

Era un medio, es verdad que era innoble, pero era un medio.

Balmaceda se alegraba, porque preveía en el debilitamiento de estos partidos, su próximo triunfo: "la dictadura", disfrazada con la reforma de la constitución, en interminables relaciones!

Así procedió también Guzmán Blanco en Venezuela; al cual sucedió el ilustre patriota, Dr. Andueza Palacios, actual presidente de aquella bella república.

Se frustaron [sic], sin embargo, los proyectos que pensaba poner en práctica el tirano.

Advertidos de los manejos indecorosos, los diversos partidos fraccionados acordaron unirse, y en las elecciones de 1888 obtuvieron una gran mayoría, designando los ministerios a voluntad del Congreso parlamentario.

Desde aquella época, dice el dictador en su célebre Mensaje leído ante "su" Congreso en 20 de abril del corriente año, surgió entre la mayoría del Congreso y el poder ejecutivo una lucha, la que tenía por objeto "subordinar la libertad y la acción del Presidente de la República", a la voluntad o los designios de una coalición compuesta de grupos políticos divididos, con caudillos y tendencias opuestas, pero todos unidos para abatir la "dignidad y autoridad" del jefe de la nación.

Mas, Balmaceda ya tenía hechas sus "cuentas", cuya "suma total" arrojaba a su favor un "saldo" cuantioso, porque no hacía figurar en las "sumas parciales", el acendrado patriotismo y valentía de los chilenos...

En breve él mismo debía reconocer su grande error...

Una grave cuestión vino entonces a avivar la lucha que acababa de terminar con las sangrientas huelgas de Valparaíso; la Ley de Contribuciones fue obstruida, como también la ley que autorizaba el cobro de los impuestos y la que fijaba las fuerzas de mar y tierra, represalia con que el Congreso contrarrestaba la obstinación completa del Presidente, que se resistía a nombrar un ministerio que contase con la confianza parlamentaria.

Era más o menos un remedo ficticio del hecho que acaeció en Inglaterra durante el reinado de Carlos I, del cual resultó la guerra entre la realeza y el Parlamento, grabando la historia el inolvidable nombre de Cromwell.

Balmaceda se prepara y lanza el reto de muerte; por un decreto suyo, anticonstitucional y criminal, ordena que se proceda al cobro de los impuestos y fija la ley que mantiene las fuerzas de mar y tierra.

Los congresistas se atraen a sí las generales simpatías del pueblo, de la escuadra y de parte del ejército.

Se principia la terrible lucha.

Ha surgido ahora l' occasion d' un stimulus, de que nos habla Corre; para el criminal innato, o se muestra el "estado latente" del criminal por incidencia o se manifiesta ante los ojos de todo el mundo, proclamándose "dictador" el 7 de enero del presente año!

Aquí principian ya a demostrarse claramente los precedentes "egocéntricos" y "síntomas episódicos", según una frase de Magnan, del hipocondriaco vesano chileno. 
Con estos antecedentes a la vista, se puede hacer un estudio físico y fisionómico de Balmaceda. Procuraremos dejar establecido el diagnóstico diferencial.

III

Es para la etiología, referente al tipo del tirano, que le vamos a estudiar y formular un diagnóstico patológico de su individualidad, para según eso poder calificar su procedimiento, abriendo la lucha fratricida en Chile.

Le conocemos ya sus antecedentes históricos; veamos ahora su fisonomía plástica, sus síntomas intelectuales y su estado somatológico, que, con más o menos precisión, conseguiremos determinarle su estado mental durante el período de la revolución y condenarlo o absolverlo con justicia.

"El rostro, dice Corre, es un retrato que refleja todo ser humano. El manifiesta el grado de la perfección de la forma exterior, el grado de la actividad cerebral y las cualidades, pasajeras o accidentales de esta actividad, los caracteres generales de las funciones fisiológicas".

Mirando a la ligera el cuadro facial de Balmaceda, nada de notable se nota; fijándose atentamente, sin embrago, con cuidado observador, en aquella fisonomía, luego se descubre en el triángulo invertido, formado por los ángulos exteriores de los ojos sombríos y la extremidad inferior de la nariz aguileña, algo que contribuye a darle un aspecto rudo.

La brutalidad y astucia se confunden con la dureza satánica de sus facciones. Tiene una cabeza grande como la de Gambetta, frente espaciosa coronada por un cráneo bien cimentado, aparentando representar ideas grandiosas, pero mui egoístas.

Dilatado debe ser su cerebelo, y pesado, cargado como está con los feroces instintos que tiene manifestados, y que le saltan los globos oculares como una suplantación ilusoria.

El rostro es ovalado, de pómulos un poco salientes, y viene estrechándose hasta llegar al cuello, largo, como el de los violentos sanguinarios.

Las orejas son regulares y pulposas; la barba es delicadamente redonda; tiene una semejanza con la barba de Henriette Cornier, el célebre monomaniaco homicida, que sirvió de asunto a uno de los más bellos estudios del notable alienista, C. Marc. La boca es grande y los labios delgados, ocultándose bajo unos sedosos y espesos bigotes que principian a encanecer. En estos últimos tiempos la solía abrir para articular rugidos de cólera, órdenes de ejecuciones temerarias, y asesinatos.

La nariz gruesa, voluminosa y aguileña, tiene cierta semejanza con el agudo pico del cóndor, el terrible rapaz de los Andes..., formando ángulo tras un pequeño surco impreso en cada lado de ella.

Los ojos, sobre todo, ese fiel espejo que refleja el interior humano, son negros, brillantes, de mirada firme y aguda como los del avestruz, queman y hieren, al abrigo de espesas y negras pestañas, describen con la fisonomía inferior del rostro un conjunto fatídico.

Su astucia, su mirada fija y penetrante y su andar acompasado y majestuoso, le imprimen un sello de autoridad temeraria y poderosa.

Su mirar duro, sanguinario y vidrioso, agitándose a veces, los párpados con movimientos casi espasmódicos, le dan a su fisonomía austera el sello del homicida apasionado, casi epiléptico!... 
En otro artículo entraremos en un análisis sucinto de las señales anamnésticas, si por acaso las tiene Balmaceda.

Un estudio completo de los signos anamorésticos de Balmaceda no podemos hacer con toda seguridad, pues ignoramos las particularidades de su infancia y pubertad. Lo que podemos afirmar es que fue arrebatado en sus amores, llegando a concebir locas pasiones femeniles.

También no hace muchos años que el tirano, por poco no fue víctima de una fiebre palúdica complicada con otros desarreglos en su organismo.

Unánimes están los más aventajados antropólogos-psicopatas en considerar las manifestaciones violentas de pasiones amorosas como causa, a veces, de una complicación en el sistema nervioso, que después puede degenerar en casos psicosomáticos declarados.

¿Quién nos podrá decir que Balmaceda haya escapado a esos peligros y que no fuese paciente de tal o cual afección en la masa encefálica, preparándose para una futura enfermedad epiléptica?

¿Quién nos podrá decir que él no pasó el primer período de esa terrible enfermedad cerebral?

El estado somático del Tirano no ofrece anomalías fisiológicas diversas de las que ya hemos apuntado.

De lo que hemos dicho se puede deducir, en presencia de un caso singular de alucinación o de locura, como el de que tratamos, lo siguiente:

(a) O Balmaceda fue un ambicioso vulgar, extraviado cuando al dar el golpe decisivo de su completo dominio y grandeza pública, vio huir en el terreno mismo de la realidad la prueba comprobatoria de su triunfo absoluto;

(b) O fue un fanático por sus ideas político-filosóficas y religiosas, que interpretó mal el sentimiento del patriotismo;

(c) O Balmaceda fue un infeliz criminal congénito, por instinto o accidental, que en su período avanzado se manifestó después impelido por una causa objetiva.

Sentados estos antecedentes históricos del tirano, opinamos por la anomalía congénita que talvez le debió afectar su organismo.

No se puede objetar que a nuestro tipo se le puede aplicar el calificativo especial que Lauvegne da a muchos hombres célebres, criminales de genio. Basta el último hecho de Balmaceda para contestarlo: la flaqueza, la cobardía vergonzosa que manifestó huyendo como un réprobo ante las filas patrióticas de los revolucionarios triunfantes en Valparaíso, en vez de lavar su nombre infamado con su propia sangre, con valor y civismo en el campo de batalla.

No nació para Marte!

No.

Balmaceda nunca pudo ser un "criminal de genio"; no pasó de ser un tipo vulgar de la clase de los "mattoides", de Lombroso.

Sufre talvez la "neurastenia moral", de Benedickt, en su período álgido. 
Las horrorosas escenas que presenció durante su dictadura, los asesinatos que ordenó cometer y los martirios a que sometió a numerosos de sus compatriotas amigos y aun parientes consanguíneos, manifiestan la cualificación que se le puede dar a su equilibrio mental, muy parecido al de un epiléptico.

Los caracteres generales más comunes, dice Legrand du Saulle, en su tratado Étude médicolégale sur les épileptiques, de los crímenes cometidos por los epilépticos, pueden resumirse en los siguientes síntomas: energía en un acto determinado; ferocidad en la ejecución del mismo; ningún disfraz para consumar el hecho; absoluta indiferencia; y ausencia absoluta de todo sentimiento de remordimiento...

El aprovechado alienista, M. de Blanche, citado por Julio de Mattos, hace en su obra Des homicides commis par les alienés, la siguiente calificación de los delincuentes epilépticos:

"En la primera categoría se puede colocar a los epilépticos impulsivos que, con mirada ardiente, rostro encendido y la mirada perturbada, se precipitan con violencia, etc. A la segunda clase pertenecen los epilépticos que espían y parecen premeditantes de llevar a cabo su agresión, etc. A la tercera división, por último, pertenecen los epilépticos que parecen inofensivos, a los cuales, además de ataques eclámpticos, se les produce en la mente una perversión verdadera. 'Estos son los más temibles de todos, actúan en virtud de una deliberación preconcebida, pacientemente, y no hacen explosión sino cuando el estado congestionado de su cerebro, manifestado por síntomas habituales, adquiere una intensidad suficiente para determinar la violencia final'".

Nos parece que a esta última categoría pertenece José Manuel Balmaceda!

Prosigamos con la última parte de nuestras consideraciones.

\section{V}

Vamos a analizar al tirano que venimos estudiando y a poner fin con este artículo a las consideraciones que nos sugieren su temperamento especial y sus particularidades singularísimas de hombre público. Puede a primera vista parecer inútil e impertinente un estudio psiquiátrico de ese hombre que nada tuvo de notable; mas, Balmaceda no es hoy simplemente el ex-presidente de Chile, no, Balmaceda es hoy un tipo, talvez el único en la historia contemporánea, del dictador perfecto, cruel en extremo, voraz, satánico, y como tal comprendido en las clasificaciones de la criminalidad antropológica, y por lo tanto, un tipo universal.

Balmaceda es un reo de lesa patria ante las naciones civilizadas; es un asesino vulgar y malvado ante la humanidad; es un fratricida ante todos sus compatriotas; ¡ es un pícaro execrable ante la conciencia de los pueblos!

Creemos que el infeliz tirano, cuando se proclamó dictador, asumiendo todo el poder público suficiente para sofocar la revuelta armada, según su propio decir, entraba al período álgido de su desenfrenada ambición, y los acontecimientos posteriores que sucedieron fueron los síntomas de una epilepsia mui avanzada.

¿Por qué demostraba él ese temor histérico de ser vencido, ese miedo nervioso que atacaba altirano al punto de hacerlo cometer los más atroces crímenes y barbaridades? 
¿Qué indica su flaqueza vil ante el ministro brasilero que le desaprobaba acremente su infame y pérfida conducta de ordenar fusilar los siete emisarios revolucionarios provistos de salvo-conductos para Valparaíso y Santiago, y que estaban bajo el amparo de las banderas francesas, americana y brasilera, insultándolas locamente de esa manera?

¿Qué denotaba su deshonrosa cobardía característica de abandonar su ejército en el mismo momento supremo de la desgracia, y huir como el Judío Errante de la leyenda?

Luego, nadie ignora que la prontitud, la violencia, el medio y la cobardía después de consumado el crimen, son síntomas morales mui comunes en los criminales epilépticos, reconocidos sin discordancia por los más aventajados profesores en psicomagia.

En cuanto al carácter de Balmaceda, se le nota mucha paridad con el de un epiléptico en el período avanzado, que es el caso de que tratamos. Refiriéndose a las particularidades especiales del individuo epiléptico, escribe el profesor Schüle, en su Manual das enfermedades mentais, citado por Julio de Mattos en el tratado A loucura, página 197:

"El carácter de los epilépticos es de una extraordinaria irritabilidad mórbida, propensa a transformarse rápidamente en actos impulsivos. Son individuos 'caprichosos y desconfiados', fáciles de excitarse contra sí mismos y contra los otros, 'turbulentos y taciturnos', ora demuestran una alegría cuya causa muchas veces ignoran, ora una tristeza exagerada, 'ya humildes y con tendencias religiosas, luego orgullosos, duros y déspotas'".

En la revista Archivio di Psichiatria, dice el señor Verga:

"Es de notar en el epiléptico, por lo general, un carácter desigual e intermitente.

Sumamente impresionable, se torna fácilmente impetuoso y colérico, ejecutando actos irreflexivos, sin cuidarse de las consecuencias posteriores que pueden traer la consumación de ellos".

Más aun, sobre este mismo tema, cita el eminente profesor portugués [sic] de Psicopatía Sessuale Krafft-Ebing, las siguientes líneas:

"A propósito debemos notar en ellos, índole anormal, vesania, humor hipocondriaco, apatía mental, irresolución, 'un estado de gran timidez y de ansiedad en vista de las menores acciones [que] va a practicar; miedo, angustia, con un carácter violento', anómalo, original, 'obstinado en sus propias ideas' e incapaz de una acción leal...".

Sin una línea de diferencia, he ahí el verdadero carácter del ex-dictador chileno, que todos pueden comprobar si recorren un poco su propia memoria, y los episodios sangrientos de guerra y exterminio que levantó contra sus propios hermanos.

Balmaceda distinguiose siempre, desde su infancia, por una contumacia excesiva, mucha violencia y accesos de irritabilidad... "La irritabilidad", escribe J. Falret, "constituye la particularidad dominante del carácter habitual de los epilépticos". Tratado De l'etat mental des épileptiques.

Mas, Balmaceda era dominado por tan violentas pasiones, tenía tanta "sed de sangre", que con la mayor indiferencia se entregó, lo mismo que un reyezuelo africano a mortificar a sus compatriotas! Los rasgos característicos objetivos del tirano se aproximan mucho a los del Melloni do Asylo de Ferrara, el cual fue objeto de estudio para el doctor Bonfigli!

A muchos legos en la materia podrá parecer admisible que Balmaceda conserve aún su "juicio sano y perfecto" después de la serie de diversos crímenes que cometió, cuando buscó por todos los medios a su alcance la fuga. 
Nada de extraño y singular, sin embargo, su conducta actual, porque sus mismos actos constituyen, cabalmente, el estilo mental del epiléctico [sic], sobre todo del epiléptico en embrión, caso en que consideramos está comprendido el tirano.

"Los epilécticos", según Delasiauve, en su Traité de l'épilepsie, "confiesan su crimen cometido, con tanta menor dificultad, cuanto que están seguros de que al haberlo ejecutado, solo han obrado en legítima defensa, obedeciendo a un instinto involuntario". Y otro profesor, cuyo nombre no recordamos, dice que la mayor parte de los epilépticos, después de sus accesos criminales de locura, vuelven a su mismo estado antiguo de buen sentido y comportamiento, dejando la duda en muchos espíritus respecto a la veracidad de su dolencia mental.

En suma, ya hemos designado su lugar al sanguinario tirano, en la galería de los delincuentes epilépticos: José Manuel Balmaceda, puede sentarse con su frente erguida en la "tercera categoría" de esos infelices, sabiamente clasificados por Blanche.

¿Merece o no el castigo correspondiente a sus perversos crímenes?

Nada nos importa decir a este respecto.

El castigo moral ya lo ha recibido de la humanidad con la maldición universal y eterna; el castigo físico incumbe únicamente a sus compatriotas y a la justicia chilena.

Merece, talvez, el castigo que se impuso el bandido de Querétaro, que quiso esclavizar a Méjico, o talvez el espacio comprendido entre los helados muros de un manicomio. Balmaceda es un reo, reo peligroso, para el cual es necesario inventar un castigo especial.

Dejamos el nombre de este feroz hombre, y que se apiade de él la bondad del Dios misericordioso que preside los destinos de las naciones, y que ve distintamente el fondo de su conciencia.

ITAGIBA.

\section{NOTA}

${ }^{1}$ Este artículo fue escrito antes de saberse en el Brasil el suicidio del dictador de Chile. 